\title{
EL COMERCIO DE LEÓN EN EUROPA (1986-2011): PASADO, PRESENTE Y ¿FUTURO?
}

\author{
José Luis Vázquez Burguete \\ e-mail: Jose-luis.vazquez@unileon.es \\ Pablo Gutiérrez Rodríguez \\ e-mail: pablo.gutierrez@unileon.es \\ Área de Marketing \\ Departamento de Dirección y Economía de la Empresa \\ Universidad de León
}

1. Introducción: orígenes del comercio leonés - 2. La pluralidad y diversidad de las formas y establecimientos comerciales: 2.1. El ciclo de vida de las formas comerciales, 2.2. Líneas generales en la evolución de las formas comerciales leonesas desde 1986 - 3. La llegada a León de los grandes competidores - 4. La difícil situación de los pequeños establecimientos: 4.1. La capacidad competitiva del pequeño comercio detallista, 4.2. Posibilidades de futuro para el pequeño comercio independiente, 4.3. Las nuevas formas de comercio asociado: 4.3.1. Asociaciones de comerciantes (calles, barrios y zonas comerciales), 4.3.2. De las galerías a los centros y polígonos comerciales - 5 . Un breve comentario en cuanto a los cambios en el comercio mayorista y la localización de centros de distribución - 6. Algunas cifras sobre el comercio en León en los últimos veinticinco años - 7. Comentarios finales y perspectivas de futuro - Referencias

"El comercio es casi un arte; es la forma inferior, el primer grado del arte" Ferdinand Brunetière

\section{Introduc ción: ońgenes del comercio leonés}

Hablar del comercio es, sin duda, referirse a una de las actividades más antiguas llevadas a cabo por la Humanidad. Sus orígenes, bajo la forma de trueque, se sitúan convencionalmente en el Neolítico, cuando el progreso de la agricultura permitió disponer de cosechas por encima de las necesidades de subsistencia de los miembros de la comunidad, al tiempo que se hacía posible derivar todo o parte del tiempo de algunos individuos para el progresivo desarrollo de otras actividades, tales como la fabricación de utensilios, enseres y herramientas, que pronto serían asimismo objeto de intercambio.

Autores como Frank Chodorov van incluso más allá en la esencia de esta afirmación, llegando a identificar a la actividad comercial en su conocido ensayo sobre el ascenso y la caída de la sociedad 
(1959) como uno de los pilares básicos -si no el fundamental- sobre el que se asienta cualquier tipo de institución social. De este modo, y frente a quienes mantienen que el origen último de los grupos sociales se debe únicamente a un instinto gregario de supervivencia, cabría postular que aquél se encuentra ligado a la necesidad de intercambio, y ello hasta el punto de resultar prácticamente imposible determinar cualquier orden de precedencia o prevalencia.

Según este razonamiento, el simple hecho de considerar que la obtención de compañía y protección en el grupo es en sí misma un intercambio (aunque no económico en términos estrictos), llevaría a este autor incluso a afirmar que los intentos de distinción en tal sentido carecerían de significado, siendo así que el mercado es el "espíritu" de la sociedad, no pudiendo existir el uno sin la otra, ni la otra sin el uno, y teniendo ambos su origen en el anhelo sin fin del hombre por una vida mejor y más plena.

El intercambio comercial puede decirse, pues, connatural a una sociedad que, a su vez, prospera con el comercio, que hace posible la especialización y, con ésta, subsecuentemente, el incremento de la producción, la reducción de costes y la dedicación de medios y recursos a la satisfacción de un número cada vez mayor de necesidades humanas.

Tal ha sido lo ocurrido en el territorio leonés, y buena prueba de ello la recurrente presencia de vestigios de almacenes en los hallazgos de asentamientos de las épocas más remotas, destinados a almacenar las mercancías objeto de comercio no sólo entre miembros de la comunidad, sino también con las comunidades vecinas. Así las cosas, la actividad comercial "hacia dentro", se vería muy pronto complementada por otra "hacia fuera", que llevaría al progresivo desarrollo de rutas de tránsito, cuya esencia básicamente comercial se combinaría, según los casos y las ocasiones, con otro tipo de propósitos, adquiriendo carta de naturaleza con las calzadas romanas, por las que tuvo lugar un asiduo discurrir de productos de tierras leonesas con destino a Roma, en una singular combinación de "comercio interior" y exportación ${ }^{1}$.

La importancia del comercio en León ha sido asimismo notable en épocas más cercanas, consolidándose en ferias y mercados llevados a cabo desde época inmemorial, avalados por fueros y privilegios medievales y que en número relativamente grande aún perviven en la actualidad (Pérez, 1998). Por ejemplo, ya el Fuero de León, dictado en 1017 por el Rey Alfonso $\mathrm{V}$, contenía preceptos para diferentes gremios de artesanos comerciantes (como los panaderos, taberneros o vinateros, carniceros y pescadores), señalando como existente "de antiguo" el mercado celebrado en la ciudad los miércoles de todas las semanas. En relación a quien trajese sus productos y viandas, al igual que a aquellos habitantes de la ciudad que las vendiesen en su propia casa, se les exhortaba a hacerlo "por recta medida y sin engaño", al tiempo que se promovía la paz en el mismo con la prohibición de perturbar el recinto en el que éste se celebraba "con armas desnudas, a saber espadas y lanzas".

Algún tiempo más tarde, Al-Idrisi mencionaba en su Dikru ál-Ándalus cómo en el siglo XII tenía lugar "un comercio muy provechoso" entre los "ahorradores y prudentes" habitantes de León (Conde, 1799), consolidándose el Barrio de San Martín como el principal asentamiento comercial de la ciudad. Esa misma importancia de la actividad comercial también se desprende de los trabajos de Méndez (1999), al señalar las peculiaridades de los sistemas de abastecimiento alimenticio de la población en el siglo XV; de Bartolomé (1999a y 1999b) y Cubillo (2000), en referencia al siglo XVIII; o de Bartolomé (2004) llegando ya hasta el siglo XIX.

\footnotetext{
1 Cabiendo entenderlo en el primero de tales sentidos por cuanto, conforme a la acepción más común del término, tenía lugar dentro de las fronteras de un territorio soberano (González, 2008), en este caso, el Imperio Romano. Y en el segundo, por cuanto es asimismo evidente que el tráfico de mercancías entre zonas geográficas o ámbitos políticos claramente diferenciados (similar a otras situaciones como, por ejemplo, en la época moderna, la coexistencia de territorios continentales, insulares y coloniales bajo soberanía española, inglesa, francesa, etc.).
} 
Respecto a los productos comercializados, se ha subrayado la importancia de los productos agrarios (Sebastián, 1992; Rubio, 1987), del pescado (Cubillo, 1998) -fundamental en la tradición de los arrieros maragatos (Rubio, 1995b)-, los tejidos (Bartolomé, 2001 y 2002), o el tabaco (Rodríguez y Gárate, 2007). En todo caso, viniendo a constituir el comercio no sólo el modo de vida de buen número de leoneses (Rubio, 1995a y 1995b), sino también constituyendo una actividad vital y de singular importancia, hasta el punto de llegar a determinar el carácter y la fisonomía de los núcleos de población (Bartolomé, 2004), particularmente los de menor tamaño, en los que ha sido claro su papel que ha desempeñado como elemento de atracción para las localidades del entorno (Vázquez y Gutiérrez, 2012).

Situados en el final del siglo XIX, y aunque sólo sea a título anecdótico, bien podría traerse aquí a colación el origen comercial de uno de los edificios que forman parte obligada de las visitas turísticas de la capital, el de la Casa de Botines, general y rápidamente asociado en el sentir popular a la actividad financiera de la
Caja de Ahorros y Monte de Piedad de León. Dicho nombre no se debe en realidad a tal vinculación, sino a una derivación del apellido de uno de sus promotores, el comerciante Joan Homs i Botinàs quien, junto con sus socios Simón Fernández y Mariano Andrés (el edificio fue también en su momento conocido como Casa Fernández y Andrés), ubicaría allí su negocio de préstamos y prendería (o compraventa de prendas y alhajas, análogo al que después desarrollaría el Monte de Piedad en esa misma ubicación) y -esto es mucho menos conocido- de tejidos (Junta de Castilla y León, 2013).

El palacete modernista construido por Gaudí entre 1891 y 1894 habría estado, en consecuencia y como tantos otros edificios, concebido en sus orígenes con un claro propósito ante todo de negocio, localizándose los pisos de residencias particulares sobre unos bajos comerciales -tal cual la gran mayoría de edificios construidos en los modernos centros urbanos- en los que convivían negocios de empeños y tejidos (almacenes incluidos).

\section{Figura 1}

\section{Un edificio emblemático con propósito comercial: la Casa de Botines}
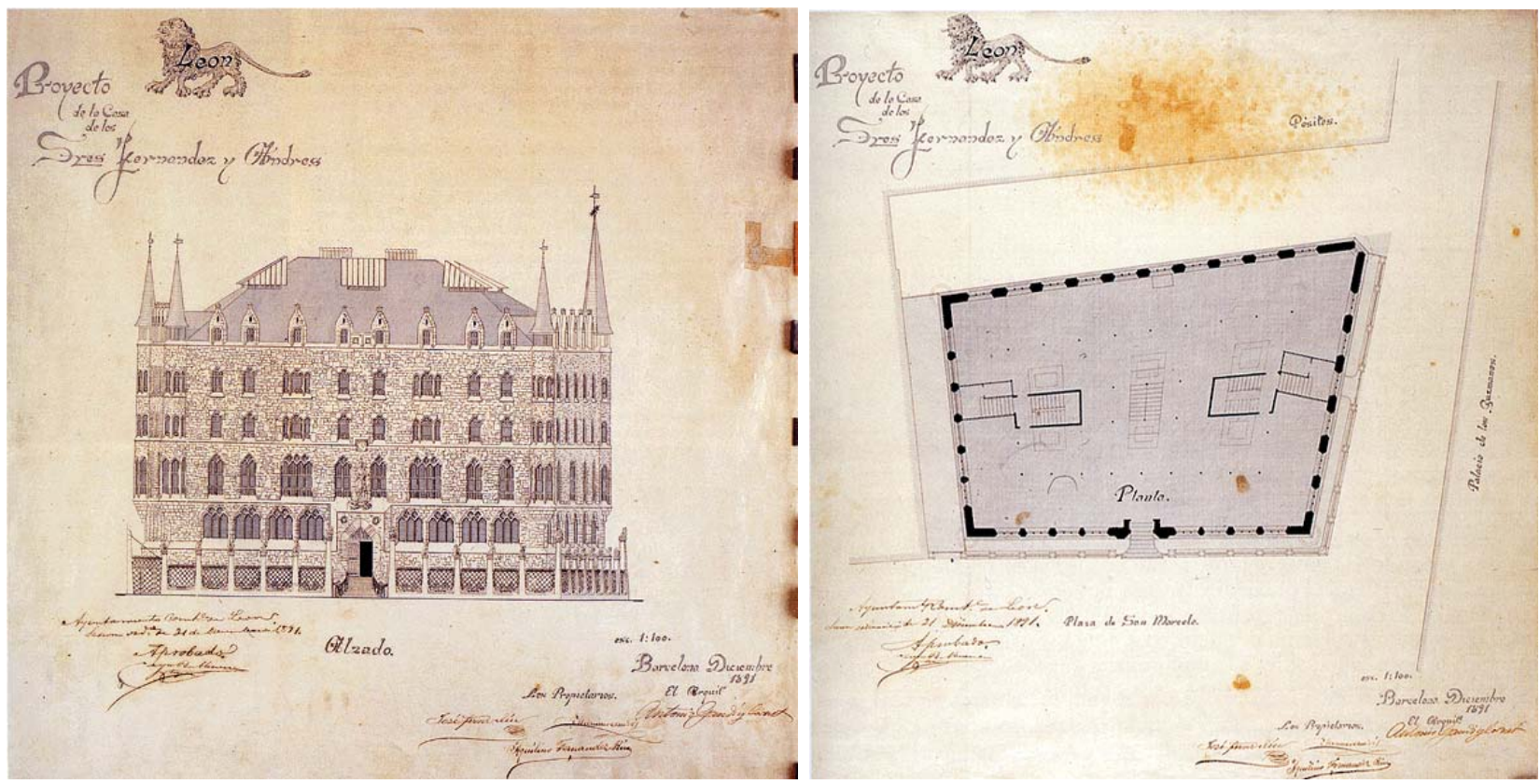

Fuente: Algorri (2000). 
Los primeros albores del siglo $\mathrm{XX}$ traerían, además, consigo un reconocimiento implícito a la importancia de la actividad comercial, con la constitución oficial en 1907 de la que, no por casualidad, llevaría el nombre de Cámara Oficial de Comercio e Industria de León y, tres años más tarde, en 1910, la de Astorga.

Precisamente la primera de dichas entidades editaba en 1957 una "pequeña historia" de la economía leonesa con motivo de su 50 aniversario. Dentro del capítulo dedicado al comercio y a los "rasgos de su evolución y su progreso", se hacía mención destacada de conocidos establecimientos de ese período, algunos ya sobradamente establecidos y otros particular- mente notorios por su novedad (García Lubén, Casa Prieto, Muebles Gago, Tejidos Mariano Andrés, o Bazar Benéitez, entre otros), con sendos apartados especialmente dedicados a González Roldán ("Historia de una Casa Comercial" resultado del esfuerzo de varias estirpes de comerciantes de paños y tejidos), y a Comercial Industrial Pallarés ("Gráfico de una Empresa Ejemplar" constituida en 1923 a partir de otras firmas comerciales previas, y que levantaría uno de los edificios más emblemáticos de la moderna fisonomía de la Plaza de Santo Domingo, análogamente a como ocurría, por ejemplo, con el establecimiento para el negocio de tejidos levantado por Cipriano García Lubén en Ordoño II).

\section{Figura 2}

Algunos establecimientos comerciales de renombre en León a comienzos del siglo XX: Comercial Industrial Pallarés y Tejidos Hijos de Francisco Roldán
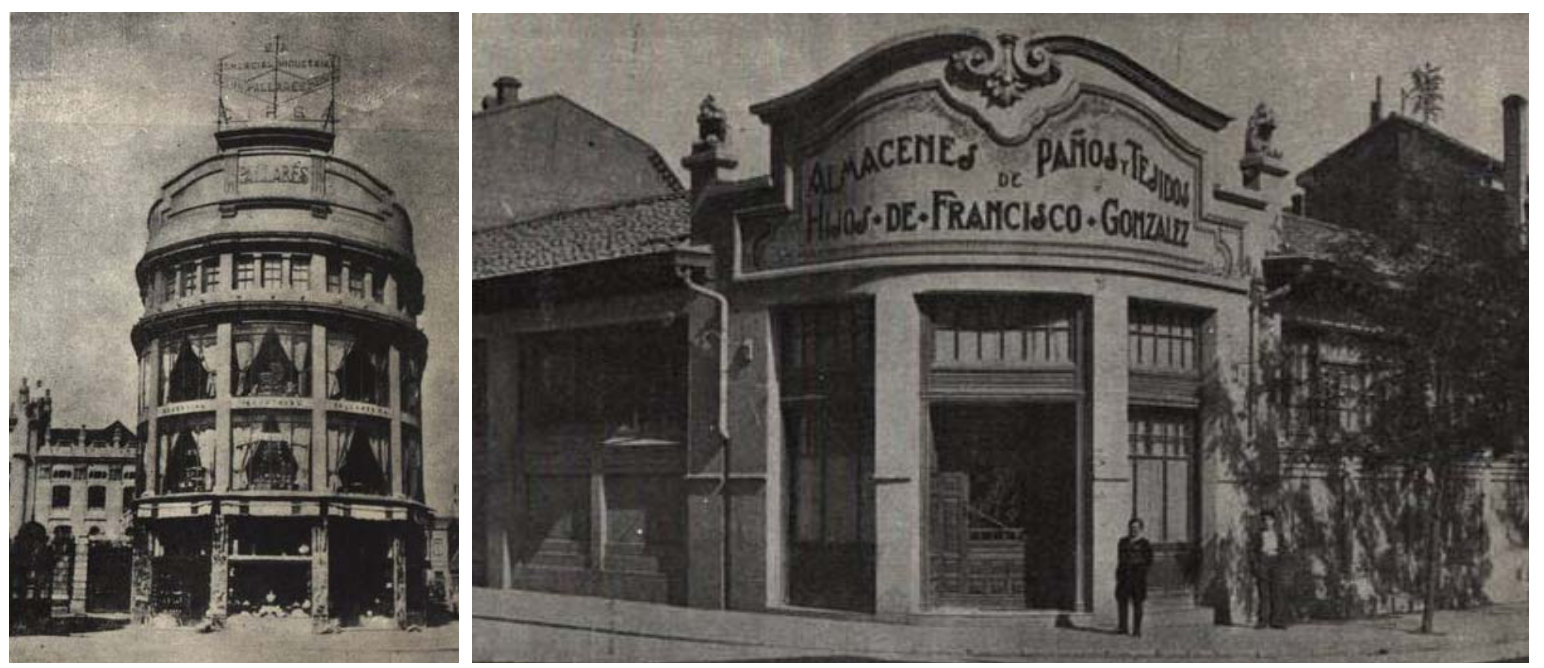

Fuente: Cámara Oficial de Comercio e Industria de León (1957).

En fin, y en términos generales, el sector, que se indicaba principalmente localizado en León, Ponferrada, Astorga y La Bañeza, era ensalzado por cuanto "si se tiene en cuenta que hace cincuenta años en toda la provincia no existían más que 430 comerciantes y ahora se lleva a una cifra que excede de los cinco mil ${ }^{2}$, fácil-

2 Haciendo referencia, por descontado, a los comerciantes establecidos y registrados en el Censo de Comerciantes. Quedarían así fuera de estas cifras mente puede colegirse que no hay en tierras de León actividad alguna económica que haya progresado tanto y en tan intensa proporción como el comercio". Se hacía también mención

tanto los particulares comerciando en ferias y mercados como la venta ambulante habitual en las zonas rurales, y a la que esta misma publicación aludía como "comerciantes de mula y alforjones", que "ni pagaban matrícula ni se colaban en los Censos Oficiales". 
como "característica destacadísima del comercio leonés [...] la calidad y belleza de sus instalaciones" (Cámara Oficial de Comercio e Industria de León, 1957: 140).

Partiendo de tan intensa y rica actividad y consecuente desarrollo de la actividad comercial, los siguientes apartados tienen por objeto mostrar la evolución en la provincia leonesa de las principales formas comerciales, con un particular hincapié en los cinco lustros a los que aluden tanto su título como el del conjunto de la obra. Se trata, pues, de echar la vista atrás sobre un pasado reciente, que hará que muchos de quienes lean estas páginas rememoren los establecimientos donde no hace tanto realizábamos las compras, su ubicación, su ambiente, sus propietarios o empleados... constatando no tanto lo rápido que pasa el tiempo como, sobre todo, los cambios vertiginosos experimentados por el sector.

En ese mismo sentido, y tras leer el contenido de las páginas siguientes, podrá constatarse cómo buena parte de los cambios más aparentes en el paisaje de los núcleos poblacionales leoneses acaecidos durante los últimos veinticinco años se deben no sólo a la construcción de viviendas y complejos residenciales, sino a que grandes edificios y superficies han surgido asociados a las nuevas formas comerciales. En paralelo, y quizá no tan perceptible en la realidad del día a día, hemos asistido a un sinfín de cierres y aperturas de pequeños establecimientos comerciales, cambios en sus nombres y en sus titularidades, en sus letreros luminosos, sus carteles y sus escaparates. Pueblos y ciudades han evolucionado a la par que lo ha hecho su comercio en una constante adaptación a los deseos y necesidades de los consumidores.

\section{La pluralidad y diversidad de las formas y establecimientos comerciales}

Siendo, pues, y ante todo, el comercio un proceso de negociación cuyo propósito es la compraventa o permuta de mercancías, no es menos cierto que éste puede tener lugar a través de muchas y plurales formas y establecimientos que se suceden y simultanean hasta el punto de dar lugar a intensos debates de académicos y expertos cuando se plantea algún intento de sistematización o clasificación.

Resultado de lo anterior, se asiste a una fuerte (y creciente) competencia entre rivales muy dispares en tamaño, cuota de mercado, posibilidades y recursos. Negocios con gran arraigo no hace tanto han tenido que hacer frente a nuevas formas comerciales más adaptadas a necesidades y estilos de vida propios de la sociedad actual y, de este modo, establecimientos en apariencia tan distintos como tiendas tradicionales (tanto las de carácter generalizado como aquellas de naturaleza especializada), cadenas de hipermercados y supermercados, grandes cadenas especializadas o grandes almacenes pueden aparecer como competidores directos en un momento dado, y ello sin olvidar las cada vez más pujantes formas de venta sin tienda u online.

\subsection{E ciclo de vida de las formas comer- ciales}

La evolución de las formas detallistas ha llevado, de hecho, a plantear diferentes teorías explicativas, ya "clásicas" en el ámbito del Marketing. Entre ellas, destaca la "rueda del comercio detallista", nueva forma o establecimiento encuentra su hueco en el mercado irrumpiendo con precios y márgenes bajos, lo que rápidamente le permite hacerse un hueco a costa de sus competidores preexistentes. Sin embargo, una posterior acción combinada de un deseo de mejora del servicio y de la imagen junto con una tendencia a la expansión por parte del comerciante, llevaría aparejada un incremento de costes a la vez que se tratan de logar mayores tasas de fidelización de la clientela, pero a costa de perder la ventaja competitiva inicial, lo que proporcionaría una oportunidad a un nuevo competidor ${ }^{4}$.

\footnotetext{
3 Cuyos postulados iniciales corresponde a Malcom McNair en 1958, siendo objeto de posterior sistematización y reformulación por parte de Stanley Hollander en 1960.

4 Tal y como se puede apreciar, se trata de un planteamiento bastante simplista, por cuanto las dos hipótesis sobre las que se sustenta resultan claramente restrictivas: por un lado, la práctica proporciona ejemplos de competidores comerciales que no entran en el mercado con una estrategia de
} 
Una alternativa a lo anterior es el denominado "ciclo de vida de las formas comerciales", modelo gráfico que, por analogía con el conocido ciclo de vida del producto, pretende explicar la evolución en el tiempo de las distintas formas del comercio detallista a lo largo de las correspondientes fases o estadios de introducción, crecimiento, madurez y declive ${ }^{5}$ (Santesmases, 2012).

De este modo, y una vez que en un momento inicial alguna circunstancia susceptible de ser transformada en ventaja competitiva (menores precios, mayor o mejor surtido, mejor localización, etc. $)^{6}$, hace posible la entrada de un nuevo competidor o forma comercial en el mercado (fase de introducción), si todo va correctamente ésta podrá experimentar un incremento relativamente grande y rápido de sus cifras de negocio (fase de crecimiento), dando lugar a beneficios que deberán cubrir no sólo los costes iniciales de entrada en el mercado que no haya compensado la fase inicial, sino también permitir la reinversión necesaria para materializar los planes de expansión y consolidación.

La estabilización de la participación en el mercado tiene lugar en un tercer estadio (fase de madurez), en el que pueden aparecer problemas asociados al aumento del tamaño y/o el volumen de negocio, como el exceso de capacidad o la multiplicación de costes, a la vez que con el tiempo surgen nuevos competidores o formas comerciales a partir de alguna nueva ventaja. Por último (fase de declive), al decaer ventas y beneficios, las formas y competidores más débiles pueden desaparecer, a no ser que encuentren algún modo de replantear su estrategia, reinventándose y readaptándose a las circunstancias del mercado y del entorno.

penetración o precios bajos; por otro, dar por hecho que las posteriores mejoras llevan necesariamente asociados incrementos de precios, sin dar opción a otras alternativas como, por ejemplo, las reducciones de costes merced a economías de escala. Más aún, cabe argumentar que el resultado "lógico" de esta teoría no sería tanto la coexistencia como la sucesión de formas comerciales.

5 Cuya formulación fue realizada por William Davidson, Albert Bates y Stephen Bass en 1976.

6 Lo cual supone un planteamiento claramente más amplio que el de McNair y Hollander.
Conforme a este planteamiento, según muestra la Figura $3^{7}$, en tanto las fórmulas más tradicionales de establecimientos al detalle, ferias y mercados de abastos se encuentran en retroceso, perdiendo peso relativo y ocupando la parte derecha de la gráfica (fase de madurezdeclive), supermercados e hipermercados ocuparían su parte superior (fase de madurez), obteniendo, por tanto, las mayores cuotas relativas del mercado.

La situación de supermercados e hipermercados, con todo, no es exactamente la misma. Unos y otros fueron implantados en España en los años setenta y han evolucionado de forma muy sensible desde entonces, pero frente a ciertos síntomas de saturación que parecen estar manifestando los hipermercados (de ahí su situación posterior al centro de la gráfica), no ha ocurrido así con los supermercados (por eso situados antes del centro de la etapa de madurez, aún en el tramo creciente de la curva) que, gracias a estar localizados más cerca del consumidor y al auge de las marcas de distribuidor de las grandes cadenas, están logrando retener una parte importante del mercado (Cuesta y Gutiérrez, 2010).

\footnotetext{
7 Correspondiente a una versión del ciclo de vida de las formas comerciales mucho más reciente, elaborada por Iglesias para el caso español en 2008. Debe tenerse en cuenta que, tal y como ya indicaban los propios Davidson, Bates y Bass, el modelo responde a un planteamiento dinámico, que requiere de una constante actualización a medida que surgen y desaparecen formas comerciales. Éstos aventuraban igualmente la eventualidad de tener que ir modificando la forma de la gráfica para adaptarla a una cada vez menor duración de las fases (aspecto éste que ha podido ser contrastado empíricamente).
} 
Figura 3

El ciclo de vida de las formas comerciales

\section{Cuota de mercado}

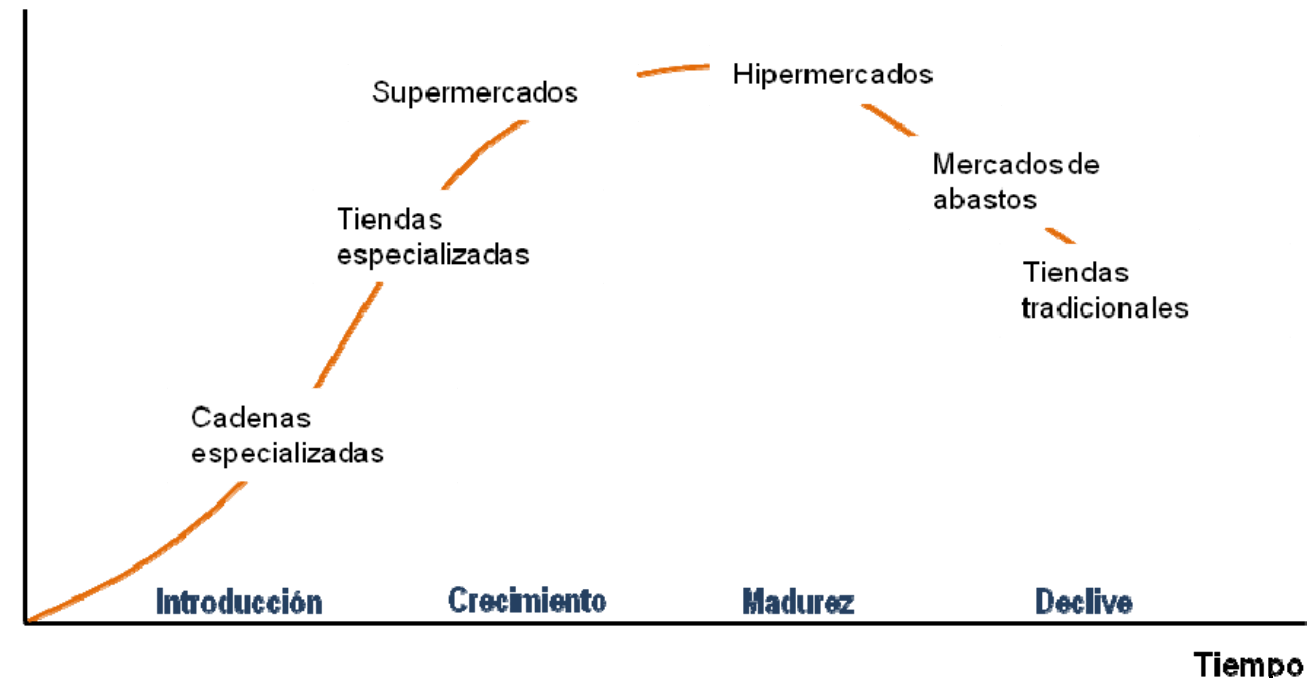

Fuente: Iglesias (2008: 42).

En paralelo, los formatos que parecen tener unas mejores perspectivas de futuro (situados en las fases de introducción-crecimiento, a la izquierda de la gráfica) son los asimismo caracterizados por un fuerte grado de especialización de la oferta, ya sea a modo de tiendas o cadenas. La razón de ello son los cambios experimentados en las tendencias de demanda y en los hábitos de unos consumidores cada vez más informados y exigentes, quienes desean escoger entre una mayor variedad de oferta y una atención más personalizada.

Tal situación se debe a la influencia combinada de diferentes factores (Vázquez y Gutiérrez, 2012). Así, tanto el consumo en masa (o consumismo) resultante de los elevados niveles de gasto incurridos en el todavía reciente período de crecimiento económico, como las restricciones propias de las etapas de recesión/ ajuste que se vienen teniendo que afrontar en los últimos años, han dado lugar a una clara segmentación del mercado de consumo, surgiendo grupos de individuos con características muy marcadas. En unos casos, con elevada capacidad de gasto (real o en determinados momentos ilusoria) e influenciados en mayor o menor medida por aspectos psicoló- gicos (aquellos demandantes de productos "de marca", o bien dispuestos a un mayor desembolso por la satisfacción de adquirir productos con connotaciones tales como "comercio justo", carácter "ecológico" o "sostenible").

Por contra, otros grupos se encuentran integrados por consumidores mucho más condicionados por su disponibilidad presupuestaria y/o concienciados por la necesidad de optimizar el gasto realizado (y por ello mismo dispuestos a llevar a cabo un mayor esfuerzo de búsqueda y comparación, de cara a lograr la mejor relación calidad-precio posible).

Incluso, cabe añadir que no deja de experimentarse un tránsito de individuos entre uno y otro grupo, en apariencia contrapuestos, pues no es tan difícil que en coyunturas como la actual, quienes se mostraban propensos a adquirir productos más caros en épocas de prosperidad se hayan convertido en expertos y reflexivos compradores que tratan de mantener niveles y estándares de vida mediante la compra de alternativas de consumo más asequibles, a la hora de la verdad con poca pérdida en términos reales de calidad y/o satisfacción, hasta el punto de haber descubierto un nuevo "sentido 
del bienestar" o de "satisfacción" en el desarrollo de esa actitud más exigente y consciente del verdadero valor de las cosas.

No debe perderse de vista, con todo, que tales cambios no han sido iniciados por las nuevas formas comerciales, o al menos no únicamente, sino que los consumidores se han visto sobre todo afectados por factores demográficos, de estilos de vida, culturales, políticos y tecnológicos que han variado su posición ante la oferta comercial. Así (Gutiérrez y Cuesta, 2009), los cambios sociodemográficos han propiciado segmentos diferenciados, como los de adolescentes (Beerli y Martín, 2012), tercera edad o upscale, muy influidos por las marcas; asimismo al aumento de hogares formados por individuos aislados o parejas sin hijos, desembocando en situaciones de alto poder adquisitivo relativo, dobles rentas y compras de artículos de lujo. Cabe también destacar los cambios acaecidos en los roles sociales, particularmente la plena incorporación de la mujer al mercado laboral, con evidentes repercusiones en la evolución de formas y aspectos comerciales (por ejemplo, el cambio de la "compra diaria" al "viaje de compra de una sola parada", y la modificación de los horarios comerciales).

Del mismo modo es evidente la influencia de los cambios operados en factores culturales (Iglesias, 2008), llegando a convertir la compra en un acto de ocio o el desarrollo de una cultura lúdica basada en las compras (García, Molina y Gómez, 2012), y promoviendo tanto la fidelidad como en ocasiones la infidelidad de los clientes (búsqueda de nuevas experiencias), o dando lugar al desarrollo de los establecimientos de restauración por el aumento de las comidas fuera de casa.

En todo caso, la capacidad del comercio para adaptarse a los cambios en los hábitos del consumidor es un hecho contrastado, lo que lleva a explicar el éxito del comercio en los últimos años como resultado de las mayores ventajas que los establecimientos ofrecen en términos de mayor variedad de productos, mejora de la atención, ampliación de horarios comerciales o diversidad de promociones de ventas y ofertas.

\section{2. Ĺneas generales en la evolución de las formas comerciales leonesas desde 1986}

Una primera aproximación a las líneas generales que han marcado la evolución de las formas comerciales en la Provincia de León durante los últimos veinticinco años viene a poner claramente de manifiesto un evidente paralelismo y similitud con lo acaecido a escala nacional $^{8}$, pero también ciertas peculiaridades. Cabe así apreciar tendencias (Vázquez y Gutiérrez, 2012):

a) En cuanto a formas de venta y tipos de establecimientos:

a.1. Pérdida relativa de importancia en el volumen total de negocio de las formas "tradicionales" de comercio especializado y de proximidad, habiendo experimentado las supervivientes distintos tipos de procesos de adaptación a la nueva realidad (ya manteniendo o renovando la esencia del negocio $\mathrm{y}$, en buen número de casos, habiendo considerado diferentes grados de asociacionismo y/o de integración -ya sea en forma de calles comerciales, barrios de comercio, zonas y/o galerías comerciales-). En particular, esta tónica evolutiva a venido a suponer la casi total desaparición de un tipo de establecimientos con características muy determinadas y presentes en múltiples pequeñas localidades, a los que se aludía genéricamente como "comercios", y en los que se podía adquirir un surtido a la vez amplio (en cuanto a variedad de artículos) y limitado (en términos de marcas) de una considerable gama de productos básicos.

a.2. Estancamiento y carácter residual de ferias y mercados periódicos (ahora ya a veces tanto y más promovidos por razones histórico-culturales que propiamente comerciales), así como de los mercados de abastos, la venta domiciliaria y las cooperativas de consumo, tanto en el ámbito rural (cooperativas de agricultores o ganaderos, en paralelo y como complemento a su actividad principal)

\footnotetext{
8 Son varios los textos y manuales donde se muestran las grandes líneas evolutivas del comercio en España. Entre ellos cabe recomendar, por su facilidad de lectura, el apartado correspondiente en el manual de Santesmases (2012).
} 
como, sobre todo, urbano (promovidas por colectivos de trabajadores de determinadas empresas o sectores, o bien grupos de vecinos, y que solían recibir el popular nombre de "economatos").

a.3. Incremento de las cadenas corporativas, paralelo a la expansión progresiva de los sistemas de franquicia, dando lugar, por ejemplo, a la práctica desaparición de los ya de por sí contados establecimientos de autoservicios y ultramarinos independientes que existían al inicio del período temporal de referencia, integrados o reemplazados por cadenas de supermercados. Y no sólo en alimentación, sino también para ropa, artículos de deporte, juguetería, droguería, perfumería..., donde las franquicias han sustituido a los pequeños establecimientos independientes.

a.4. Progresiva implantación y consolidación de formas comerciales de mayor surtido y amplia superficie, como hipermercados y grandes almacenes.

a.5. Progresiva implantación de formas mixtas de asociacionismo, en las que coexisten pequeños comercios y grandes establecimientos en una misma superficie, como ocurre en centros y polígonos comerciales.

a.6. Fuerte irrupción de una amplia categoría de establecimientos de descuento, en los que normalmente se puede adquirir una muy amplia gama de productos (recordando en este sentido lo que era habitual en los "comercios" antes mencionados, pero con la notable diferencia de no haber oferta de productos de alimentación -o ser ésta prácticamente anecdótica-).

a.7. Creciente coexistencia de los habituales establecimientos físicos con otras formas comerciales en ausencia de los mismos, como las máquinas de vending o, en particular, la compra desde el domicilio (por catálogo, teléfono o televisión) y, sobre todo, con un gran incremento de las asociadas a nuevas tecnologías (tiendas online en Internet). En unos casos como formas de negocio independientes $y$, en otros en el marco de una estrategia multicanal de gestión de relaciones con los clientes (Cambra, Melero y Sesé, 2012). b) En cuanto a la utilización de instrumentos de marketing:

b.1. Creciente importancia de elementos asociados a la calidad de los productos (incluyendo etiquetado y otras informaciones, garantía postventa, etc.), en respuesta a la mayor educación y los mayores requisitos y exigencias de un consumidor cada vez más preocupado por la relación calidad-precio.

b.2. Surgimiento de nuevos segmentos de consumidores con demandas muy específicas y creciente conciencia social (productos ecológicos, comercio justo...).

b.3. Incremento paralelo del uso de marcas de distribuidor (identificadas con unos mayores o menores estándares de calidad, según los casos) y de las marcas blancas.

b.4. Disminución de la importancia relativa de las campañas de comunicación de masas, y mayor efectividad de los sistemas directos (en particular, el boca-oreja).

b.5. Mayor libertad y amplitud de horarios y días comerciales, así como de formas de ofertas y descuentos más allá de los períodos de rebajas establecidos legalmente, en paralelo a una progresiva desregulación (o ampliación de posibilidades conforme a la normativa, si se prefiere).

\section{La llegada a León de los grandes competidores}

Siendo evidente la mayor importancia comercial de los grandes centros urbanos en relación con los pequeños núcleos de población, puede decirse que ésta resulta incluso mayor a partir de la segunda mitad del siglo pasado (años sesenta y setenta), por la confluencia de circunstancias tales como los movimientos migratorios del campo a la ciudad, el incremento de la renta disponible y el desarrollo del turismo (interno y externo), todo ello dando pie a nuevos sistemas de distribución masiva, en los que el papel de las grandes cadenas y grandes establecimientos con ventas en régimen de autoservicio iba a ser cada vez mayor (Vázquez y Gutiérrez, 2012). 
Así las cosas, y junto a unos pequeños establecimientos de comercio tradicionales cuya cuota de mercado se ha visto sensiblemente reducida en los últimos años, es cada vez más significativa la importancia que vienen adquiriendo grandes organizaciones comerciales como son los supermercados, hipermercados y grandes almacenes (las cuales, por otra parte, vienen también experimentando un proceso de concentración), que poseen un gran poder de compra y de control sobre los canales de distribución y utilizan constantemente innovaciones en técnicas de venta y de gestión a la vez que sus mayores recursos de cara a una mejor adaptación a los cambios en las condiciones del entorno.

Tal situación de dualismo no equilibrado provoca cambios significativos, entre los que se cuenta un flujo constante de consumidores a favor del segundo tipo de establecimientos, cuya presencia y aparentes ventajas son fácilmente percibidas por aquéllos. Es fácil comprobar cómo las primeras posiciones en los rankings de distribución en España están ocupadas por este tipo de negocios.

En tal sentido, no debe perderse de vista el hecho de que, merced a su posición intermediaria en la cadena de valor, los establecimientos minoristas no sólo mejoran la utilidad de los productos al proporcionarles servicios añadidos, sino que también detentan una posición intermediaria entre fabricantes o mayoristas y consumidores, cuya tipología de actuaciones contribuye a caracterizar los tipos de establecimientos existentes (Betancourt y Gautschi, 1993).

Por un lado, servicios como localización, acceso y conveniencia facilitan la compra del consumidor, introduciendo el elemento geográfico en el análisis competitivo del sector. Los comerciantes minoristas compiten horizontalmente en los mercados de consumo final, debiéndose tomar como unidad de análisis la ubicación del establecimiento (localidad, barrio, calle), a la vez que una paralela competencia vertical exige una referencia nacional, europea o global, puesto que la forma de competir en los mercados industriales también lo es (Sanchís, 1993; Cruz et al., 1999), llevando a limitar la capacidad de maniobra de los pequeños minoristas, quienes han de utilizar como unidad de análisis las empresas o grupos en que se encuentren asociados, en su caso, los establecimientos y el mercado en que compiten (normalmente nacional y ocasionalmente internacional).

En este mismo sentido, cuando se analizan los productos que componen la cesta de la compra, es necesario tener en cuenta que la estructura de competencia horizontal y vertical es muy diferente por categorías o tipos de productos. Así, por ejemplo, en el caso de una cesta de compra de productos de alimentación, las tiendas tradicionales vienen presentando mayores cuotas de mercado (como formato comercial) en productos frescos, mientras que supermercados e hipermercados las logran en productos secos o envasados.

Por otro lado, la posición intermediaria antes aludida permite al comercio minorista, y en particular a los grandes competidores del sector, aprovechar el poder que le otorga un mercado fiel o vinculado territorialmente, haciéndolo valer como elemento de fuerza para negociar condiciones ventajosas en la adquisición de los productos. Esto supone que, en la medida en que mayores cuotas de consumidores relevantes para los fabricantes se encuentren bajo el control o influencia de los minoristas, éstos adquirirán un mayor control del canal de distribución y podrán obtener ventajas en la negociación de algunos aspectos explícitos o implícitos en las condiciones o contratos de compra.

Hay que tener en cuenta que los minoristas pueden trabajar con hasta cuatro tipos de marcas en su surtido: marcas líderes, no líderes, de distribuidor y marcas blancas. La competencia intratipo y entre tipos de marcas es diferente. En marcas líderes la competencia intermarca es relativamente baja (gran diferenciación de los productos frente a los de la competencia), mientras que la competencia entre establecimientos minoristas es relativamente alta, por lo que son un buen instrumento para formar una imagen de establecimiento exclusivo y de calidad. Para los otros tipos la competencia intermarcas es más acusada en el interior de un mismo establecimiento, y el papel del precio muchas veces determinante.

Algún tiempo después de la aparición en la Provincia de León de las primeras cadenas de 
alimentación ${ }^{9}$, así como en otros productos de comercio, la inauguración del hipermercado Continente (posteriormente Carrefour, tras la fusión con Pryca) a las afueras de la capital leonesa el 26 de noviembre de 1990 supuso un punto de inflexión en el sector de la distribución, con un gran eco social, por cuanto la ciudad y su entorno pasaban a considerarse de facto un punto de consumo lo suficientemente importante como para "justificar" la presencia de un establecimiento de estas características.

La oferta de hipermercados se ha ampliado posteriormente con los centros de E. Leclerc en terrenos de Trobajo del Camino (1995), Eroski en La Bañeza (2004) -ver Figura 4- y un nuevo Carrefour en Ponferrada (2007).

No obstante, la verdadera "revolución" comercial tuvo lugar con la llegada de El Corte Inglés en $1994^{10}$, máximo exponente de los grandes almacenes en España ${ }^{11}$, y con todas las connotaciones asociadas a este establecimiento ${ }^{12}$.

9 Previo al período aquí considerado, experiencias como la asociación de tiendas de ultramarinos a la cadena Spar anticiparon la más reciente implantación de cadenas de supermercados como El Árbol, Alimerka o Rozas, a los que seguirían Gadis, Lidl, Mercadona, Eroski y, más recientemente, Aldi.

10 Si bien el centro en la capital leonesa entraba en los planes del grupo desde veinte años antes.

11 En particular, tras desaparecer Galerías Preciados. No obstante, El Corte Inglés no fue el primer gran almacén de características similares ubicado en León, sino que éste fue Almacenes Morais, inaugurado en 1973 y desaparecido en 1979, tras cambiar su denominación un año antes a Olwo.

Pese a que la vida de este establecimiento cae fuera del período temporal de referencia en estas páginas, consideramos de justicia su mención, tanto por su carácter pionero en el mundo de los grandes almacenes, como por tratarse de una muestra del talento emprendedor leonés.

12 No sólo en términos de cuota de mercado y de presencia física, ya sea el centro principal u otros subsidiarios (hipermercado, centro de viajes, tiendas de moda, centro liquidador), sino también por su atractivo como demandante de empleo y su presencia en la vida social y cultural.

\section{Figura 4}

La llegada de hipermercados y grandes almacenes revoluciona el comercio y se plantea como un acontecimiento social

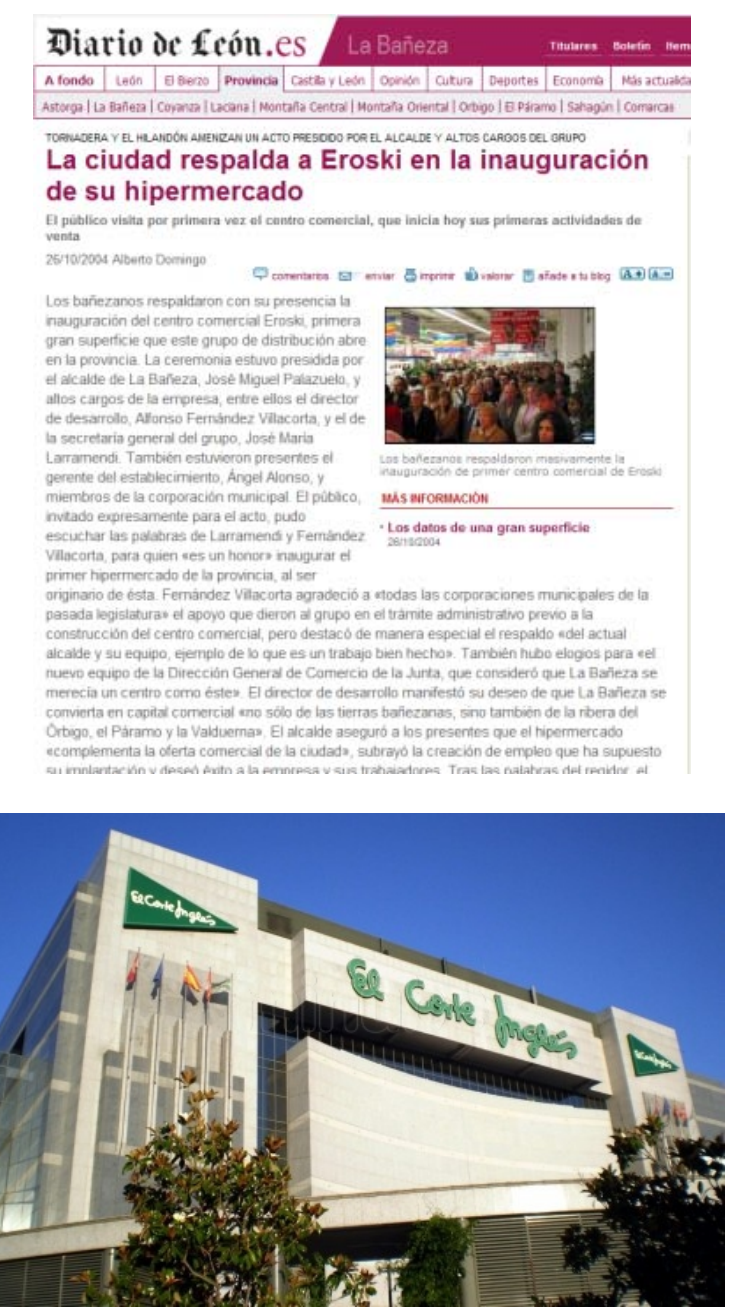

Fuente: http://www.diariodeleon.es/.

\section{La difícil situación de los pequeños establecimientos}

Frente a los grandes competidores, pervive un sistema clásico de comercio, conformado por pequeños establecimientos de proximidad, mucho más limitados en recursos y equipamientos, cuya cuota de mercado decreciente les sitúa en muchos casos en una situación de difícil pervivencia, traducida en una alta rotación y progresivo cierre de negocios. 
El nuevo contexto (control del sector por los grandes competidores, cambios en hábitos de consumo, reducción de márgenes de rentabilidad, etc.) obliga a quienes compiten en este subsector a modificar actitudes y pautas de actuación, a fin de poder aplicar de forma efectiva estrategias diferenciadas frente a las grandes superficies. De hecho, las funciones de demanda de las grandes superficies y el pequeño comercio tradicional son distintas y, tras la competición y reajuste inicial, deberían quedar claramente diferenciadas, conforme ya ha ocurrido en otros países de nuestro entorno. El objetivo de los pequeños comercios deberá ser, pues, tratar de fidelizar a quienes disponen del tiempo y la capacidad adquisitiva necesarios para hacer de la compra algo "especial", alejado de servirse a uno mismo en las estanterías en el menor tiempo posible. En otras palabras, competir por quienes no renuncian a disfrutar de los momentos dedicados a la compra ${ }^{13}$, aprovechando las ventajas de lo que se ha dado en llamar "valor" o "capital de marca" de los pequeños establecimientos (Gil et al., 2012).

\subsection{La capacidad competitiva del pequeño comercio detallista}

Pese a los malos augurios es, pues, más que posible y necesaria la existencia de un hueco de mercado para el pequeño comercio, siempre y cuando sea capaz de desarrollar las estrategias adecuadas para mantenerlo, aspecto éste que ha captado la atención y sido singular objeto de consideración por parte de los expertos. Recuérdese en tal sentido que se está haciendo referencia a grupos de consumidores que demandan un servicio que vaya "más allá", o un trato más personalizado.

En el Cuadro 1 se muestran los principales puntos fuertes y débiles que, desde el punto de vista de la competitividad, tienen los pequeños establecimientos de comercio frente a los grandes competidores del sector.

\section{Cuadro 1}

Principales puntos fuertes y débiles desde un punto de vista competitivo del pequeño comercio frente a los grandes competidores

\section{Puntos débiles}

- Pérdida relativa de peso (cuota de mercado) del comercio tradicional independiente frente a las grandes cadenas asociadas, hipermercados y grandes almacenes.

- Menor disponibilidad de todo tipo de recursos (equipamientos, formación, financiación, instrumentos comerciales...).

- Menor poder de negociación con proveedores y consecuentes desventajas términos de costes y precios.

\section{Puntos fuertes}

- Posibilidad de un contacto más directo, estrecho y personalizado con el consumidor.

- Mayor flexibilidad y capacidad de adaptación de procedimientos de gestión y de la labor de la fuerza de ventas, lo cual, junto a lo anterior, aumenta las posibilidades de fidelización.

- Control directo de la gestión por parte de los propietarios de los establecimientos o empleados muy próximos a éstos.

Fuente: Basado en Trespalacios (2008: 159).

13 Ideas que ya se avanzaban en un artículo de opinión sobre "La evolución del comercio en León" (Muñiz y Vázquez, 1995), publicado tras la apertura de Toys'R'Us junto al entonces hipermercado Continente, contribuyendo así a conformar un claro polígono comercial (figura asociativa a la que se hará referencia posteriormente). 
Los puntos débiles contenidos en el cuadro precedente están interrelacionados, pues la mayor afluencia de clientes a los grandes establecimientos o cadenas asociadas deviene tanto de la debilidad en la capacidad de negociación con proveedores y los consiguientes precios superiores en pequeños establecimientos como de los mayores recursos ( $y$, por tanto, mejor y más fácil acceso a medios y acciones) para publicidad, promoción y merchandising de los grandes competidores, o incluso para la formación de sus empleados. Las menores ventas reducirán, a su vez, la capacidad de negociación y la disponibilidad de recursos para la actualización de establecimientos y procedimientos, entrando de este modo en un círculo vicioso de muy difícil solución.

Con todo, también hay puntos fuertes que deben ser aprovechados. Así, y tanto y más que en otros pequeños y medianos negocios, el pequeño comerciante suele mantener un contacto directo y estrecho con el consumidor, lo cual le permite un conocimiento directo e inmediato de sus deseos y una atención personalizada de los mismos, frente a los procedimientos habituales en la mayoría de grandes cadenas y establecimientos, donde priman el régimen de autoservicio, los procedimientos estandarizados y los ahorros en costes de personal.

En paralelo, no se puede negar que el pequeño comercio, aun con menos recursos, es más flexible y posee mayor libertad para cambiar el surtido o seleccionar segmentos de mercado (en tanto los grandes competidores casi siempre acuden a mercados de masas para poder ser rentables, lo que les hace ser más rígidos en sus planteamientos de ofertas comerciales), a la vez que puede motivarse más fácilmente a los empleados identificándolos con la misión y cultura del negocio y con el logro de resultados, gracias al control directo de la gestión por parte del empresario comerciante.

\subsection{Posibilidades de futuro para el pequeño comerc io independiente}

De este modo, las posibilidades de supervivencia del pequeño comercio independiente pasan por la elección e implantación de una adecuada estrategia, en la que habrán de estar presentes elementos tales como la especialización en surtido, la buena localización y la mayor satisfacción al consumidor a partir del diseño de los correspondientes servicios comerciales pre y post-venta (Trespalacios, 2008).

Así, no es casualidad que la mayoría de pequeños establecimientos se hayan especializado (salvo cada vez más contadas excepciones de oferta generalista en pequeñas poblaciones, en los que concurren razones de proximidad o incluso limitaciones de acceso desde/a los grandes núcleos comerciales). Para ello es preciso acertar con un surtido atractivo y dar un servicio adecuado a las expectativas de un consumidor dispuesto a pagar un precio superior.

Una buena localización es otro de los factores clave de éxito cuando tiene lugar un aumento de los clientes potenciales, si bien los mayores costes de compra o alquiler que supone pueden ser inalcanzables.

En todo caso, debe tenerse siempre presente que el consumidor, a mayores de un beneficio funcional derivado de la utilidad de lo adquirido, suele buscar un beneficio simbólico reflejado en aspectos más cualitativos y/o sutiles, como la conformidad de la imagen del establecimiento comercial con su estilo de vida, la confianza que le inspira el comerciante, o el trato amistoso -o bien podría decirse que incluso familiar- de quien le atiende. El umbral o nivel mínimo de expectativas a satisfacer, aunque más elevado ( $y$, por ende, más difícil de satisfacer a cada día que pasa) y superior a lo que el cliente espera encontrar en los grandes establecimientos de autoservicio, se constituye también en una de las mayores oportunidades de diferenciación o incluso una tabla de salvación para los comercios detallistas de menor tamaño.

A la vista de todo ello, los establecimientos de pequeño comercio independiente leonés han optado por diferentes estrategias de supervivencia. Así, y a mayores de la imprescindible renovación de métodos de gestión y atención al público, o al margen de las posibles formas asociativas a las que se hará posterior referencia, unos han optado por una imagen de "sabor" asociada a la conservación de una larga "tradición" comercial, en tanto otros lo han hecho 
por una mucho más "evolucionada" o vinculada a la "modernidad", gozando unas y otras fórmulas del reconocimiento de un público leal a según qué tipo de establecimientos (Vázquez y Gutiérrez, 2012).

\subsection{Las nuevas fomas de comerc io asociado}

En paralelo a la renovación y adaptación de los pequeños comercios, y desde hace ya tiempo, muchos expertos apuestan por las estrategias de crecimiento externo como posibles y únicas vías para afrontar los nuevos tiempos (Sanchís, 1993), ya sea mediante fusiones/adquisiciones o a través de la cooperación.

Un proceso de fusión/adquisición resulta en un aumento del tamaño del negocio, lo que supone mayores cifras de ventas y recursos, mejorando las posibilidades de acceso a economías de escala, nuevas tecnologías, métodos de producción y comercialización, y mercados de materias primas, a la vez que aumenta el poder de negociación con proveedores y son factibles, en mayor o menor medida, todas las ventajas genéricas de supermercados, hipermercados y grandes almacenes. Empero, tampoco debe olvidarse que las fusiones/adquisiciones también suponen una reducción en el número de competidores y la intensidad competitiva, lo cual puede no ser a la postre bueno ni para la oferta ni para la demanda, hasta el punto de haberse llegado a postular que un proceso intenso de concentración por esta vía en el sector de la distribución comercial en España no haría sino potenciar, aún más si cabe, las formas de supermercado e hipermercado, eliminando por completo al pequeño negocio de comercio minorista.

Frente a lo anterior, otra alternativa de crecimiento externo es explorar vías de cooperación o desarrollo de alianzas estratégicas. La cooperación, entendida ésta en un sentido amplio tanto a nivel conceptual como de formas y procedimientos (subcontratación, franquicia, consorcios, acuerdos funcionales, empresas conjuntas, redes cooperativas, etc.), conlleva las mismas ventajas que una fusión/ adquisición, pero con el añadido de mantener la independencia jurídica y/o de titularidad de las entidades asociadas, la mayor flexibilidad en cuanto a surtido y especialización así como en cuanto a la segmentación y, lo que puede ser más importante, conservando el tamaño pequeño de los negocios asociados. No obstante, la cooperación suele ser difícil de mantener, debido a la exigencia de la existencia de un beneficio mutuo y un acuerdo equilibrado entre los socios. Esta opción estratégica ha obtenido significativos éxitos puntuales al ser adoptada por determinadas cooperativas de consumo españolas, a la vez que ha logrado su mayor exponente en las franquicias y cadenas de comercio especializado.

\subsubsection{Asoc iaciones de comerciantes (calles, bamios y zonas comerciales)}

Ligadas al desarrollo de las posibilidades cooperativas han surgido figuras específicas que, si bien conservan la independencia del establecimiento asociado, van cobrando carta de naturaleza como tales formas asociativas a la par que sus símbolos y logotipos se integran en el paisaje comercial de los núcleos mayores de población, haciéndolas merecedoras, cuando menos, de una sucinta referencia. Todas ellas suponen interesantes experiencias de gestión innovadora que comparten el objetivo común de que las ciudades sigan teniendo un centro urbano dinámico y atractivo, lo cual hace necesario no tanto conservar como "reinventar" los espacios comerciales y de ocio a través de las correspondientes estrategias de revitalización urbana, una gran mayoría de las veces basada $-y$ posible gracias a ella- con la colaboración público-privada (Rovira, Forés y Hernández, 2012).

Tal es el caso de formas de asociación espacial de negocios llevadas a cabo en diferentes lugares al objeto de dinamizar los correspondientes emplazamientos e incrementar el atractivo y la imagen de los establecimientos por medio de un espíritu colectivo independiente, promocionando de manera conjunta una amplia oferta comercial o incluso organizando con carácter puntual actividades de ocio, eventos deportivos u otras actividades de carácter sociocultural. En la Provincia de León varias son las experiencias de este tipo que se han traducido en experiencias pioneras o en éxitos dignos de mención.

Así, por ejemplo, y más allá de la localización o identificación popular (e informal) de determinados emplazamientos con calles o zonas comer- 
ciales, cabe mencionar la Asociación Leonesa de Comercio (ALECO), la Asociación de Comerciantes de Bembibre (ACOBEM), la Asociación de Empresarios de Astorga y Comarca (ASEMAC), o la Asociación de Comerciantes de la Zona de La Bañeza (AGEBA). En algunos casos se trata de asociaciones integradas únicamente por establecimientos comerciales (asociaciones específicas), en tanto en otros casos conviven con empresas del sector industrial (asociaciones no específicas).

Más ligadas a zonas concretas son otras experiencias vinculadas al fomento y defensa de los establecimientos de proximidad que conforman el "comercio de barrio", apoyadas por campañas institucionales a nivel regional y municipal, dada la crítica situación que vienen atravesando estos negocios en términos competitivos (aspecto éste ya mencionado), acrecentada aún más por la difícil coyuntura económica reciente (haciendo al consumidor más sensible al precio). Entre ellas, la Asociación de Comerciantes de la Zona de El Crucero.

Finalmente, tanto y más amplios en este sentido son los objetivos de las asociaciones promotoras de "centros comerciales abiertos" (frente a los espacios cerrados referidos a continuación), como la Asociación de Establecimientos Comerciales Independientes Centro León Gótico, y la Asociación Local de Empresas Centro Comercial Abierto de Ponferrada (La Cebra).

\subsubsection{De las galeńas a los centros y polígonos comerciales}

Mucho más ambiciosos que las galerías comerciales (de las que podría decirse que son sus predecesores a pequeña escala), los centros comerciales son una forma asociativa que ofrece al consumidor una amplia oferta ubicada en un mismo espacio físico específicamente destinado a esta finalidad (a diferencia de los centros comerciales abiertos) combinada con servicios de ocio y la organización habitual de actividades. Si bien en ocasiones este formato agrupa únicamente a pequeños establecimientos (buscando el modo de hacer frente a los grandes competidores por medio de la combinación de la oferta de una amplia gama de productos), es más habitual que algún gran competidor (hipermercado o cadena) se encuentre también presente, aumentando el atractivo del emplazamiento y dando así lugar a lo que puede considerarse una forma asociativa mixta entre pequeños y grandes establecimientos, tal y como es el caso de los tres localizados en León.

Si la apertura de hipermercados y grandes almacenes fue planteada en su momento como un acontecimiento social, más allá de los cambios en el comercio, otro tanto cabe decir de la más reciente inauguración de los tres grandes centros comerciales de la provincia (Figura 5).

\section{Figura 5}

Los centros comerciales: una nueva revolución comercial de la mano del asociacionismo
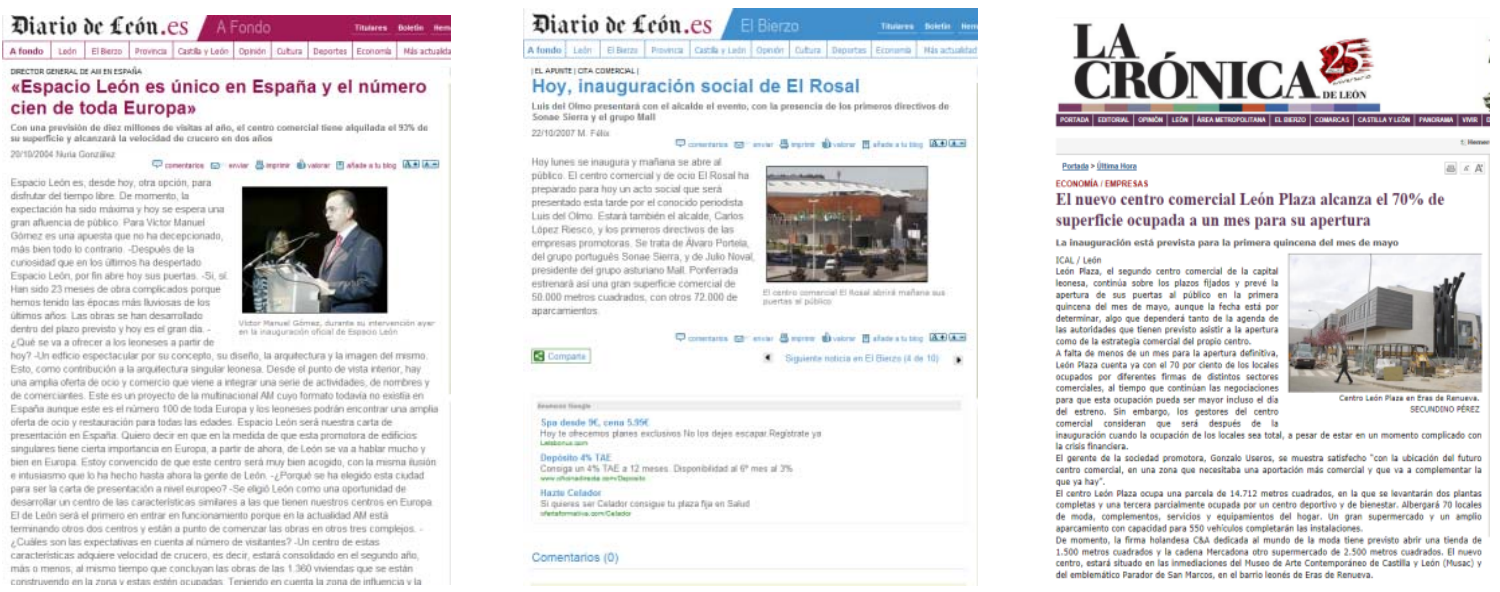

Fuente: http://www.diariodeleon.es/ y http://www.la-cronica.net/. 
El primero de ellos, el Centro Comercial y de Ocio Espacio León, fue inaugurado en la capital el 20 de octubre de 2004, de la mano del Grupo AM, contando con una capacidad de $37.000 \mathrm{~m}^{2}$ brutos disponibles para más de 120 tiendas y 1.500 plazas de aparcamiento. Los grandes competidores con mayor presencia en dicho emplazamiento son la cadena Media Markt y El Corte Inglés, con un Supercor. Junto a ellos, se encuentran otros como Zara, Forum Sport, $H \& M$, y así hasta completar una amplia lista de franquicias y establecimientos.

Tres años después, el 22 de octubre de 2007, abría oficialmente sus puertas el Centro Comercial y de Ocio El Rosal, en Ponferrada, cuyos $50.653 \mathrm{~m}^{2}$ alquilables para 144 establecimientos y 2.500 plazas de aparcamiento lo convertían por tamaño en aquel momento en el más grande de la provincia y segundo gran centro comercial del noroeste español ${ }^{14}$, tras el Parque Principado de Oviedo, también promovido por el grupo portugués Sonae Sierra, en colaboración con el Grupo Mall ${ }^{15}$. En éste, y junto al poder de atracción ejercido por el hipermercado Continente, la oferta comercial inicial se completaba con cadenas como Zara, Bershka, Pull \& Bear, Oysho, H\&M, C\&A, New Yorker, Desigual, Stradivarius, Massimo Dutti, Promod, Cortefiel, Women'Secret y establecimientos locales.

Más reciente en el tiempo, y de la mano del Grupo Norte, el 22 de mayo de 2009 se inauguraba en León el Centro Comercial León Plaza, cuyos $18.000 \mathrm{~m}^{2}$ disponibles para unos 70 locales y algo más de 500 plazas de aparca-

14 Si bien El Rosal continúa siendo el mayor centro comercial en León, ya no es el segundo del noroeste español, tras la reciente apertura en 2011 del tercer complejo comercial más grande de Europa en La Coruña, cuyos $170.000 \mathrm{~m}^{2}$ dan buena idea de sus colosales dimensiones, hasta el punto de haber cambiado su inicial denominación Marineda Plaza por la más acorde de Marineda City Ocio, Shopping $\&$ Business.

15 Sonae Sierra sigue presente en El Rosal, encargándose de la administración del centro tras el acuerdo suscrito en marzo de 2011 con su nuevo propietario, la sociedad de capital-riesgo Doughty Hanson \& Co. Real Estate (también propietario de otros centros de estas características, como el Plaza Éboli, ubicado en la localidad de Pinto-Madrid-). miento lo presentan como claramente más reducido que su más inmediato y cercano competidor (Espacio León), frente al que apuesta por una localización más cercana al centro urbano y una mayor presencia de establecimientos locales allí deslocalizados. Junto a éstos, y al supermercado Mercadona, cadenas como C\&A, Juguettos o Bodybell.

Finalmente, dentro de este epígrafe cabe mencionar el desarrollo de los que se han dado en denominar "polígonos comerciales". Se trata en este caso de una forma asociativa, pero no tanto por haberse planteado como tal por parte de los comerciantes que en un momento dado se encuentran allí instalados, sino más bien por el simple hecho de haber llegado a producirse de facto, por cuanto que así lo determina la localización en un espacio relativamente reducido de una amplia oferta comercial más o menos diversificada, pero en la que la característica del asociacionismo no está necesariamente presente ${ }^{16}$ (sino que más bien viene determinada por las posibilidades o permisibilidad de la oferta urbanística, reservando terrenos o emplazamientos con esta finalidad).

En algunas ocasiones se trata de naves que combinan la actividad industrial con la venta al por mayor y venta al detalle en similares condiciones (autoservicio, menores precios y servicios añadidos, etc.) y en otra de negocios comerciales propiamente dichos, en todo caso ubicándose fuera de los núcleos urbanos o en los cinturones periféricos, tal y como ocurre, por citar tan solo un ejemplo, en torno al hipermercado Carrefour de León, dentro del cual existe una galería comercial en la que se ubicaban el primer McDonald's de la Provincia, y actualmente un Burger King y otros pequeños establecimientos, y junto al que ya desde el principio (en parcelas anexas) se localizaban Toys'R'Us y Feuvert (del mismo grupo que el entonces Continente). Más recientemente, la oferta se iría completando con el supermercado Día (también parte del Grupo Carrefour), el

16 Esto no quita que en ocasiones puedan compartirse gastos de señalización o medios publicitarios, o incluso facilidades para el cliente como aparcamiento (por ejemplo, por tratarse de establecimientos de un mismo propietario, o en virtud de algún acuerdo puntual de colaboración). 
centro liquidador de El Corte Inglés, establecimientos de bricolaje y relacionados con el mantenimiento de vehículos.

Entre los casos más recientes, si no el que más, se encontraría la progresiva localización en las inmediaciones de Mercaleón de los establecimientos de Lidl, McDonald's (por reubicación del previamente existente junto a Carrefour) y Gadis.

\section{Un breve comentario en c uanto a los cambios en el comerc io mayorista y la loc alización de centros de distribución}

Si bien las páginas precedentes se han centrado en los cambios acaecidos en el comercio detallista durante los últimos veinticinco años, no es menos cierto que algunas novedades surgidas en el comercio mayorista resultan igualmente reseñables. De este modo, y junto a la pervivencia del comercio al por mayor, ya sea como actividad asociada al establecimiento industrial o propia del mayorista comercial, exclusiva o en combinación con la venta al consumidor final (según se indicaba algunas líneas más arriba), en los últimos años se ha asistido a la implantación de una forma específica de comercio mayorista en el sector de la alimentación y/o restauración, los cash \& carry, de los que existen diferentes ejemplos en la Provincia de León.

Junto a ellos, las actividades más tradicionales de este mismo sector, esto es, las relacionadas con los productos frescos perecederos, han dado lugar a complejos mayoristas específicos, como el de los Mercados Centrales de Abastecimiento de León (Mercaleón), entidad constituida en 1989 por parte del Ayuntamiento de León y la Empresa Nacional Mercados Centrales de Abastecimiento (Mercasa).

Y fuera ya de lo que sería la actividad comercial propiamente dicha, pero íntimamente ligada a las grandes cadenas de distribución, cabe también hacer referencia a los grandes centros logísticos que se han localizado en León en los últimos años, refrendando el valor estratégico de la provincia a estos efectos (connatural a su posición inmejorable para articular las relaciones del noroeste español con el centro y otras zonas de la península, así como en algunas rutas de tránsito del norte portugués hacia España y Europa), a la par que contribuyendo significativamente al empleo local.

Los ejemplos más notorios en este sentido son, sin duda, la plataforma logística del Grupo Inditex en la segunda fase del Polígono Industrial de Onzonilla en octubre de 2006, y el centro logístico de Mercadona en el Polígono Industrial de Villadangos en junio de 2010, cuya tecnología es instalaciones hacen que en el sector logístico sea considerado el "almacén del siglo XXI".

\section{Algunas cifras sobre el comercio en León en los últimos veinticinco años}

Contrariamente a lo que se pueda pensar, no es fácil separar los datos del comercio minorista y mayorista a lo largo de los últimos años en España. Además, a diferencia de lo que ocurre con otros sectores económicos, los datos disponibles de la evolución del comercio nacional y provincial desde 1986 son prácticamente inexistentes en los primeros años, debido a la dispersión y fragmentación de las fuentes a las que se debe acudir para retroceder tantos años en el tiempo. En concreto, las referencias más fiables (aunque incompletas) se encuentran en sendas publicaciones del Instituto Nacional de Estadística: el Censo de Locales Comerciales (de 1980 y 1990) y el Directorio Central de Empresas (DIRCE). Además de lo comentado, otra de las limitaciones para el análisis de este sector se puede encontrar en la propia división de la clasificación de los locales dedicados al comercio al por mayor, al comercio minorista y a la venta, mantenimiento y reparación de vehículos de motor y motocicletas. Este último epígrafe (actualmente apartado 45 de CNAE 2009) incluye tanto a locales dedicados al comercio minorista como a mayorista, concretamente "esta división comprende todas las actividades (excepto las de fabricación y alquiler) relacionadas con vehículos de motor y motocicletas, incluidos camiones y vehículos pesados, como la venta al por mayor y al por menor de vehículos nuevos y de segunda mano, la reparación y el mantenimiento de vehículos y la venta al por mayor y al por menor 
de repuestos y accesorios para vehículos de motor y motocicletas. Se incluyen también las actividades de intermediarios del comercio al por mayor y al por menor de vehículos, las subastas al por mayor de automóviles y la venta al por mayor por Internet. Esta división comprende también actividades como el lavado, el encerado de vehículos, etc. Esta división no comprende la venta al por menor de carburantes y productos lubricantes o refrigerantes para la automoción ni el alquiler de vehículos de motor o motocicletas" (INE, 2012). Este desglose de los datos deberá ser tenido en cuenta, aunque serán los datos referentes al número de locales, empleados o ingresos de las organizaciones establecidas como minoristas y mayoristas sobre los que se podrá obtener mayores conclusiones.

El análisis de la contribución de un sector al Valor Añadido Bruto (VAB) de la economía es uno de los indicadores más utilizados para poder determinar la relevancia de ese sector en el global de la economía del país. Los datos del VAB a precios básicos expresados a precios corrientes y desglosados por ramas de actividad son publicados por el Instituto Nacional de Estadística (INE) como parte de la Contabilidad Nacional de España. Se puede observar que, en los últimos datos disponibles que corresponden al año 2010, el VAB del comercio alcanzó más de 116.000 millones de euros, lo que representa el 12,2 por 100 del VAB total de la economía. En la evolución de la contribución del $V A B$ del comercio al $V A B$ total en la última década, se observa una tendencia creciente de la importancia del sector comercio y reparación en el total de la economía, provocada en parte por el escaso crecimiento del VAB total nacional. De esta forma, la contribución del comercio al VAB total ha pasado del 11,2 por 100 en 2000 al 12,2 por 100 en 2010.

Si hablamos de empleo, el sector comercio viene aglutinando en los últimos tiempos en torno al $14 \%$ del total de ocupados en la economía española (el 13,8\% en 2012, conforme a los datos medios anuales de la Encuesta de Población Activa), proporción que se ha mantenido relativamente estable desde el inicio de la década. Dentro de este sector, y como cabe esperar (por el mayor número de establecimientos), es el comercio al por menor el que registra el mayor número de ocupados (cercano a la décima parte del total de ocupados de la economía nacional, el 9,0\% en 2009, más del $65 \%$ del total del empleo en el sector).

Estos datos permiten una primera aproximación a la importancia del comercio en España pero, para completar el análisis y establecer una comparación entre la evolución acaecida y la experimentada en la Provincia de León, debe recurrirse al número de locales comerciales en los tres diferentes tipos de comercios que establecen las estadísticas.

De este modo, y a partir de los correspondientes datos (Gráfico 1), pueden observarse características muy claras, tanto para el comportamiento nacional como el provincial, particularmente análogo en el caso de los últimos diez años. Desde 1986 se ha producido un importante aumento en el número de locales mayoristas, ralentizado de manera notable con el principio de siglo, con la consiguiente estabilidad o estancamiento a partir de ese momento. Las cifras concretas muestran, desde 1986, un incremento muy significativo hasta la actualidad (de casi el $216 \%$ en España y del $162 \%$ en León), aunque más acusado en los primero años. En la última década también podemos encontrar porcentajes de crecimiento positivos (del $17 \%$ en España y del $13,8 \%$ a nivel provincial).

Caso contrario es el de los otros comercios, los locales de venta, mantenimiento y reparación de vehículos a motor y motocicletas y los minoristas, que muestran un nivel de locales similar al de 1986 a nivel nacional, situación contraria a la de la Provincia de León, donde la cifra en los últimos años es incluso sensiblemente inferior respecto al primer año de análisis. 
Gráfico 1

Evolución del número de locales comerciales minoristas y mayoristas en España y en la Provincia de León (1986-2011)
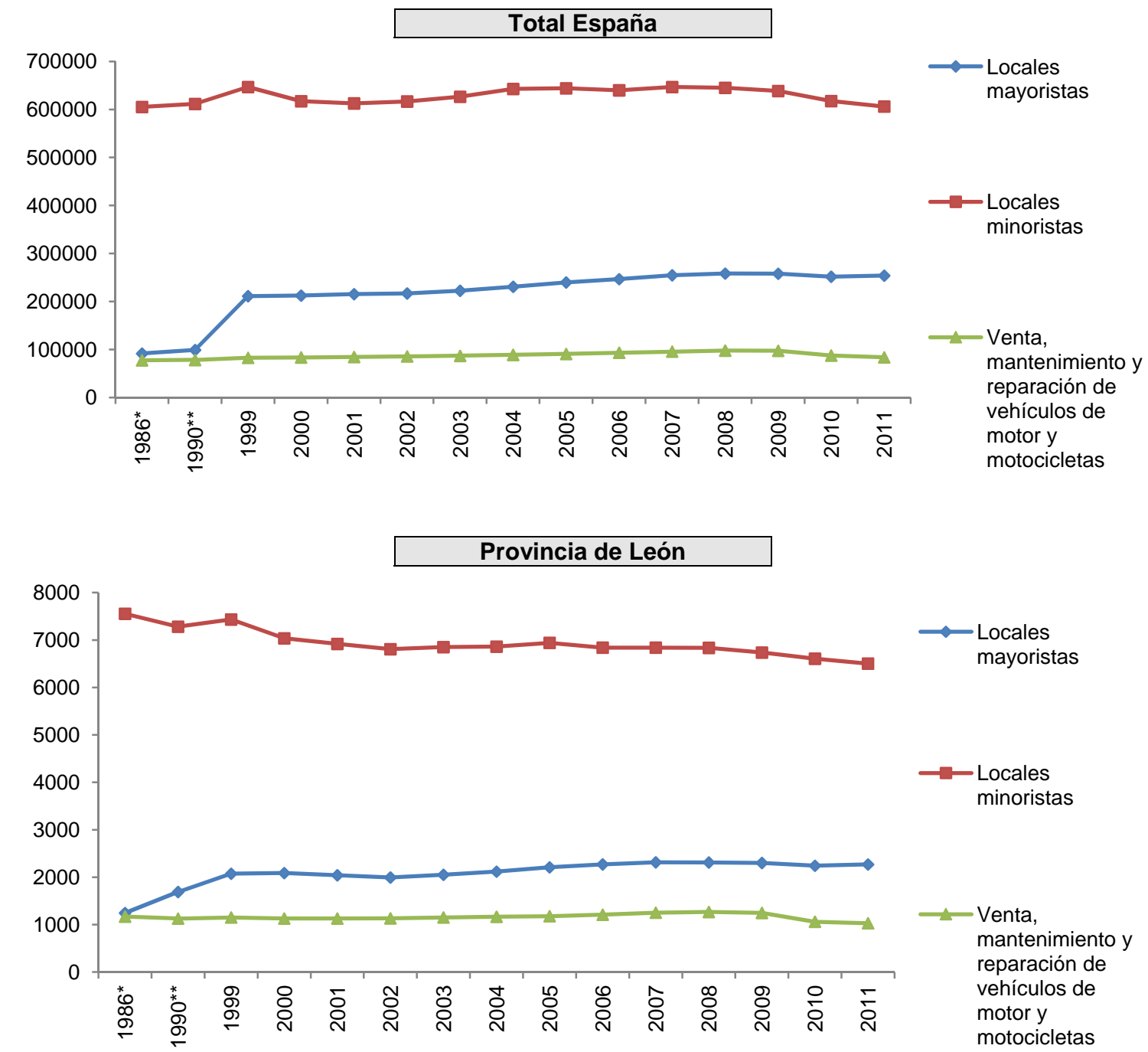

* Estimación en base al Censo de Locales de España, 1980.

** Estimación en base a los datos del Censo de Locales de España, 1990.

Fuente: Elaboración propia en base a los datos del DIRCE (INE).

Más en concreto, y en cuanto a locales minoristas, las cifras nacionales se muestran decrecientes (descenso del $1,7 \%$ en la última década y el 1,8 desde 1986), llegando a mayores pérdidas porcentuales de locales en el caso de León (el 4,5\% y 14,6\% respectivamente).
Por último, el comportamiento de los locales de venta, mantenimiento y reparación de vehículos a motor y motocicletas ha mostrado pérdidas en ambos periodos de análisis, más significativas desde 1986 (de casi el 9,9\% en España y del $12,6 \%$ en León) que en la última década (también deficitaria, con el 2,3\% en España y del $9,1 \%$ en la provincia leonesa). 
Tabla 1

Porcentaje de locales de la Provincia de León en relación con el total nacional (1986-2011)

\begin{tabular}{|c|c|c|c|}
\hline Año & Locales minoristas (\%) & Locales mayoristas (\%) & $\begin{array}{c}\text { Venta, reparación y mantenimiento de } \\
\text { vehículos (\%) }\end{array}$ \\
\hline $1986^{*}$ & 1,25 & 1,36 & 1,51 \\
\hline 1990 & 1,19 & 1,70 & 1,44 \\
\hline 1999 & 1,15 & 0,98 & 1,39 \\
\hline 2000 & 1,14 & 0,98 & 1,35 \\
\hline 2001 & 1,13 & 0,95 & 1,33 \\
\hline 2002 & 1,10 & 0,92 & 1,32 \\
\hline 2003 & 1,09 & 0,92 & 1,33 \\
\hline 2004 & 1,07 & 0,92 & 1,31 \\
\hline 2005 & 1,08 & 0,92 & 1,3 \\
\hline 2006 & 1,07 & 0,92 & 1,3 \\
\hline 2007 & 1,06 & 0,91 & 1,31 \\
\hline 2008 & 1,06 & 0,89 & 1,3 \\
\hline 2009 & 1,05 & 0,89 & 1,28 \\
\hline 2010 & 1,07 & 0,89 & 1,21 \\
\hline 2011 & 1,07 & 0,89 & 1,23 \\
\hline
\end{tabular}

* Estimación en base al Censo de Locales de España, 1980.

Fuente: Elaboración propia en base a los datos del DIRCE (INE).

Pormenorizando un poco más en la situación descrita, la Tabla 1 permite apreciar cómo viene teniendo lugar una pérdida continuada, en términos de importancia relativa, del comercio de León sobre el total nacional. En tanto el comercio minorista leonés suponía el 1,25\% del total nacional en 1986 y sólo el 1,07\% en 2011, el comercio mayorista registraba un descenso mucho más acusado, pasando del 1,36\% de 1986 a tan solo el $0,89 \%$ en 2011 , similar a la pérdida de importancia de los locales con actividades sobre vehículos a motor, que pasaban del $1,51 \%$ al $1,23 \%$ en los años indicados.

De la observación de toda la serie se desprende que el descenso más importante, en todos los casos, se produjo en la década de los noventa, cuando el comercio minorista leonés se redujo del $1,25 \%$ al $1,15 \%$, en tanto el porcentaje del comercio mayorista lo hacía del 1,36\% al 0,98\% y los locales de venta, mantenimiento y reparación de vehículos a motor y motocicletas pasaron del 1,51\% al 1,39\%.

Considerando la importancia relativa de los diferentes tipos de establecimientos, la evolución del comercio leonés es bastante similar a la del conjunto nacional, si bien con algunas diferencias (Tablas 2 y 3). Mientras los mayoristas en León crecían un 11\% desde 1986 y su importancia relativa era mayor que en España al principio del período, en el conjunto de la nación el porcentaje se incrementaba en más del 15\%, gracias sobre todo a las subidas registradas en los años noventa. 
Tabla 2

Importancia relativa del comercio minorista y mayorista en la Provincia de León y en España (1986-2011)

\begin{tabular}{|c|c|c|c|}
\hline Año & Locales minoristas (\%) & Locales mayoristas (\%) & $\begin{array}{c}\text { Venta, reparación y mantenimiento de } \\
\text { vehículos (\%) }\end{array}$ \\
\hline $1986^{*}$ & 75,78 & 12,49 & 11,73 \\
\hline 1990 & 72,11 & 16,73 & 11,16 \\
\hline 1999 & 69,74 & 19,46 & 10,80 \\
\hline 2000 & 68,63 & 20,36 & 11,00 \\
\hline 2001 & 68,58 & 20,23 & 11,19 \\
\hline 2002 & 68,53 & 20,07 & 11,40 \\
\hline 2003 & 68,15 & 20,40 & 11,45 \\
\hline 2004 & 67,63 & 20,88 & 11,49 \\
\hline 2005 & 67,21 & 21,39 & 11,41 \\
\hline 2006 & 66,28 & 22,01 & 11,72 \\
\hline 2007 & 65,73 & 22,24 & 12,03 \\
\hline 2008 & 65,64 & 22,19 & 12,17 \\
\hline 2009 & 65,50 & 22,37 & 12,13 \\
\hline 2010 & 66,68 & 22,63 & 10,70 \\
\hline 2011 & 66,34 & 23,15 & 10,51 \\
\hline
\end{tabular}

* Estimación en base al Censo de Locales de España, 1980.

Fuente: Elaboración propia en base a los datos del DIRCE (INE).

En el resto de locales, en uno y otro caso, se producen descensos en ambos ámbitos geográficos de maneras muy similares. Los locales minoristas han visto reducido su porcentaje sobre el total a lo largo del todo el período (si bien de forma casi inapreciable en el último lustro) y los locales de venta, mantenimiento y reparación de vehículos a motor y motocicletas han visto como se producía la mayor caída en los últimos cuatro años.

\section{Tabla 3}

\section{Importancia relativa del comercio minorista y mayorista en España (1986-2011)}

\begin{tabular}{|c|c|c|c|}
\hline Año & Locales minoristas (\%) & Locales mayoristas (\%) & $\begin{array}{c}\text { Venta, reparación y mantenimiento de } \\
\text { vehículos (\%) }\end{array}$ \\
\hline $1986^{\star}$ & 78,18 & 11,82 & 9,99 \\
\hline 1990 & 77,53 & 12,56 & 9,91 \\
\hline 1999 & 68,76 & 22,45 & 8,79 \\
\hline 2000 & 67,59 & 23,26 & 9,15 \\
\hline 2001 & 67,14 & 23,60 & 9,26 \\
\hline 2002 & 67,09 & 23,59 & 9,32 \\
\hline 2003 & 66,96 & 23,77 & 9,27 \\
\hline 2004 & 66,79 & 23,97 & 9,24 \\
\hline 2005 & 66,08 & 24,60 & 9,31 \\
\hline 2006 & 65,32 & 25,16 & 9,52 \\
\hline 2007 & 64,86 & 25,54 & 9,59 \\
\hline 2008 & 64,45 & 25,79 & 9,76 \\
\hline 2009 & 64,25 & 25,95 & 9,80 \\
\hline 2010 & 64,54 & 26,31 & 9,15 \\
\hline 2011 & 64,23 & 26,90 & 8,86 \\
\hline
\end{tabular}

* Estimación en base al Censo de Locales de España, 1980.

Fuente: Elaboración propia en base a los datos del DIRCE (INE). 


\section{Comentarios finales y perspectivas de futuro}

Varias son los comentarios que, a modo de conclusión, cabe realizar a partir del contenido de las páginas precedentes. De este modo, y si bien, tanto a nivel nacional como provincial el comercio sigue siendo uno de los sectores con mayor peso relativo dentro de la actividad productiva, tanto en términos de su aportación al valor añadido bruto como de empleo, no es menos cierto que se están operando significativas transformaciones en las formas comerciales y en la titularidad de los establecimientos, configurándose cada vez más como un sector con una estructura de carácter oligopolístico con un número muy reducido de grandes competidores dominando los formatos más relevantes (grandes almacenes, hipermercados, supermercados y cadenas especializadas), en los que la dinámica competitiva inter e intratipo es cada vez más intensa.

Paralelamente, el más perjudicado es el pequeño comercio independiente, el cual pierde cada vez más peso dentro de un contexto en el que son palpables sus desventajas, particularmente en términos de mayores costes y precios, menor amplitud de oferta y menores recursos disponibles frente a las grandes superficies o a las grandes cadenas de establecimientos asociados o franquiciados.

En el caso de León, esta situación se aprecia no sólo con echar un vistazo al paisaje comercial, sino a través de los datos disponibles. Baste así ver el cada vez menor número de locales comerciales activos, particularmente en lo que atañe al pequeño comercio minorista especializado. Del mismo modo, la pérdida de importancia relativa del comercio minorista leonés frente al total nacional, o el estancamiento (sobre todo en los años más recientes) de los ratios de locales comerciales en relación con el total nacional y en función del número de habitantes.
Así las cosas, y aunque todo parece apuntar a que los diferentes formatos comerciales no son incompatibles, sino que todos pueden mantener una cierta cuota de mercado en función de púbicos objetivo y estrategias diferenciadas, el problema más relevante desde el punto de vista de potencial destrucción de empleo e impacto social viene a ser plantear posibles alternativas para la supervivencia del pequeño comercio minorista local. Entre las opciones con mejores resultados se encuentran las fórmulas de asociacionismo espacial y en centros abiertos, tratando así de trasladar los puntos fuertes de los grandes competidores (incluidos los centros comerciales cerrados) a zonas concretas de los cascos urbanos, aprovechando las posibilidades de uso de una imagen y métodos de gestión común, en tanto se conserva la propiedad independiente.

En paralelo, y junto a otros cambios en modas y patrones de consumo, las recientes épocas de crisis han dado lugar a individuos más informados y formados, conscientes del valor de su tiempo disponible, el trato recibido y la necesidad de un mejor aprovechamiento de sus recursos logrando una buena relación calidad-precio. Surgen así nuevas oportunidades para quienes sean capaces de adaptarse y aprovechar las ventajas en cuanto a trato y proximidad, flexibilidad y gestión directa, propias de los pequeños establecimientos. La clave para éstos radica no sólo en la especialización del surtido y la calidad de los productos, sino también en el conocimiento del cliente, el trato flexible y la posibilidad de aconsejarle, generando un clima de confianza y cercanía que contribuya a fidelizar determinados segmentos o masas críticas de individuos.

En tal sentido, el uso de nuevas tecnologías debe ayudar al pequeño y mediano comercio a ampliar los límites de búsqueda de mercados y clientes más allá de las fronteras locales, a la par que tratando de satisfacerlos con estrategias diferenciadas. 


\section{Referencias}

Algorri, E., Dir. (2000). León, casco antiguo y ensanche. Guía de arquitectura. León: Colegio Oficial de Arquitectos de León.

Bartolomé, J.M. (1999a). La situación de los portazgos, pontazgos y barcajes de la provincia de León en el siglo XVIII según los informes del intendente. Estudios Humanísticos. Geografía, Historia y Arte, (21), 141-154.

Bartolomé, J.M. (1999b). Los problemas de abastecimiento de una villa vitícola en el Antiguo Régimen: Ponferrada en el siglo XVIII. En J.M. González, J.L. Pereira y J.M. De Bernardo (Coords.), La administración municipal en la Edad Moderna (pp. 359-366). Cádiz: Asociación Española de Historia Moderna.

Bartolomé, J.M. (2001). El comercio leonés de hilos e hilazas en el siglo XVIII. Stvdia Historica. Historia Moderna, (23), 233-248.

Bartolomé, J.M. (2002). La dinámica en la producción y consumo de textiles en León: las zonas artesanales de La Bañeza y Astorga (1700-1860). Investigaciones Históricas. Época Moderna y Contemporánea, (22), 117-140.

Bartolomé, J.M. (2004). El tránsito al crecimiento económico en León (1750-1850). Condiciones de vida y pautas de consumo. León: Universidad de León.

Beerli, A. y Martín, J.D. (2012). Eficacia de las promociones para productos de compra por impulso en el target de los jóvenes. En R. Vázquez, J.A. Trespalacios, E. Estrada y C. González (Coords.), Estrategias multicanal en el ámbito de la distribución: fabricante y distribuidor preocupados por ofrecer nuevas experiencias de compra diferenciadas (pp. 19-41). Oviedo: Cátedra Fundación Ramón Areces de Distribución Comercial.

Betancourt, R. y Gautschi, D. (1993). Two essential characteristics of retail markets and their economic consecuences. Journal of Economic Behaviour and Organization, 21(3), 277-294.

Cámara Oficial de Comercio e Industria de León (1957). Economía leonesa: pequeña historia de su evolución 1907-1957. León: Publicaciones de la Cámara Oficial de Comercio e Industria de León. Edición digital disponible en http://bibliotecadigital. jcyl.es/ (consultada a fecha 10 de enero de 2013).

Cambra, J., Melero, I. y Sesé, F.J. (2012). La gestión de las relaciones con los clientes en un contexto multicanal. En R. Vázquez, J.A. Trespalacios, E. Estrada y C. González (Coords.), Estrategias multicanal en el ámbito de la distribución: fabricante y distribuidor preocupados por ofrecer nueva s experiencias de compra diferenciadas (pp. 43-62). Oviedo: Cátedra Fundación Ramón Areces de Distribución Comercial.

Chodorov, F. (1959). The rise and fall of society. An essay on the economic forces that underlie social institutions. New York: The Devin-Adair Company.

Conde, J.A. (1799). Dikru ál-Ándalus / Descripción de España de Xerif Aledris, conocido por El Nubiense. Madrid: Imprenta Real (edición virtual de la Biblioteca Cervantes, disponible en http://www.cervantesvirtual.com/).

Cruz, I., Yagüe, M.J., Rebollo, A. y Oubiña, J. (1999). Concentración y competencia en la distribución minorista en España. Información Comercial Española. Revista de Economía, (779), 9-36.

Cubillo, R. (1998). El pescado en la alimentación de Castilla y León durante los siglos XVIII y XIX. León: Universidad de León.

Cubillo, R. (2000). Comer en León: un siglo de historia, 1700-1800. León: Universidad de León. 
Cuesta, P. y Gutiérrez, P. (2010). El equipamiento comercial de los centros comerciales en España. Distribución y Consumo, (110), 110-121.

Davidson, W.R., Bates, A.D. y Bass, S.J. (1979). The retail life cycle. Harvard Business Review, 54(6), 89-96.

García, J.A., Molina, A. y Gómez, M. (2012). ¿Compras u ocio? Un análisis de la distribución del tiempo de los consumidores en un centro comercial. En R. Vázquez, J.A. Trespalacios, E. Estrada y C. González (Coords.), Estrategias multicanal en el ámbito de la distribución: fabricante y distribuidor preocupados por ofrecer nueva s experiencias de compra diferenciadas (pp. 63-78). Oviedo: Cátedra Fundación Ramón Areces de Distribución Comercial.

Gil, I., Ruiz, M.E., Berenguer, G. y Corraliza, A. (2012). El capital de marca de la tienda: un análisis comparado hipermercado versus tienda especializada. En R. Vázquez, J.A. Trespalacios, E. Estrada y C. González (Coords.), Estrategias multicanal en el ámbito de la distribución: fabricante y distribuidor preocupados por ofrecer nueva s experiencias de compra diferenciadas (pp. 79-98). Oviedo: Cátedra Fundación Ramón Areces de Distribución Comercial.

González, A. (2008). El comercio en la España Interior durante la época moderna. Obradoiro de Historia Moderna, (17), 15-42.

Gutiérrez, P. y Cuesta, P. (2009). Upscale marketing. En J. Sánchez y T. Pintado (Coords.), Estrategias de marketing para grupos sociales. Madrid: ESIC.

Hollander, S.C. (1960). The wheel of retailing. Journal of Marketing, 24(3), 37-42.

Iglesias, V. (2008). Los mercados de abastos. En J.M. Pérez y B. Álvarez (Coords.), Estudios sobre la competitividad del comercio minorista urbano (pp. 15-40). Oviedo: Seminario de Estudios de Comercio de Asturias (SECA).

Junta de Castilla y León (2013). ArteHistoria. La página del Arte y la Cultura en Español. http://www.artehistoria.jcyl.es/ (consultada a fecha 10 de enero de 2013).

McNair, M.P. (1958). Significant trends and developments in the post war period. En A.B. Smith (Ed.), Competitive distribution in a free high level economy and its impact for the university (pp. 1-25). Pittsburgh: University of Pittsburgh Press.

Méndez, C. (1999). El abastecimiento de la ciudad de León en la Edad Moderna. En J.M. González, J.L. Pereira y J.M. De Bernardo (Coords.), La administración municipal en la Edad Moderna (pp. 391-400). Cádiz: Asociación Española de Historia Moderna.

Muñiz, N. y Vázquez, J.L. (1995). La evolución del comercio en León. La Crónica 16 de León, 3.515 (17/11/1995), VI (supl. Economía 16).

Pérez, M.J. (1998). Ferias y mercados en la provincia de León durante la Edad Moderna. León: Universidad de León.

Rodríguez, J.M. y Gárate, M. (2007). El monopolio español de tabacos en el siglo XVIII. Consumos y valores: una perspectiva regional. Madrid: Altadis.

Rovira, A., Forés, D. y Hernández, C. (2012). Gestión innovadora de centros comerciales urbanos. Modelos y experiencias. Gijón: Trea.

Rubio, L. (1987). La Bañeza y su tierra, 1650-1850. Un modelo de sociedad rural leonesa. León: Junta de Castilla y León.

Rubio, L. (1995a). La burguesía maragata: dimensión social, comercio y capital en la Corona de Castilla durante la Edad Moderna. León: Universidad de León.

Rubio, L. (1995b). Arrieros Maragatos. Poder, negocios, linaje y familia. Siglos XVI-XIX. León: Fundación Hullera Vasco-Leonesa. 
Sanchís, J.R. (1993). Análisis del comercio minorista en España: un enfoque estratégico. Estudios sobre Consumo, (28), 50-57.

Santesmases, M. (2012). Marketing. Conceptos y estrategias ( $6^{\mathrm{a}}$ ed.). Madrid: Pirámide.

Sebastián, J.A. (1992). Propiedad señorial, captación del producto agrario y estrategias de comercialización: el ejemplo de un monasterio leonés de comienzos del siglo XVI a 1835. Noticiario de Historia Agraria, 2(4), 251-276.

Trespalacios, J.A. (2008). Conocimiento y formación: elementos claves en la capacidad competitiva del comercio minorista. En Pérez, J.M. y Álvarez, B. (Coords.), Estudios sobre la competitividad del comercio minorista urbano (pp. 155-179) Oviedo: Seminario de Estudios de Comercio de Asturias (SECA).

Vázquez, J.L. y Gutiérrez, P. (2012). Veinticinco años del comercio en León: nuevos vientos, nuevas realidades. En Gutiérrez, N. (Dir.), M.T. Cosmen y J.L. Placer (Coords,), XXV años de economistas y economía leonesa (pp. 83-105). León: Colegio de Economistas de León y Eolas Ediciones.

\section{Fuentes estadísticas}

INE: Censo de Locales Comerciales de España (1980 y 1990). Directorio Central de Empresas (varios años, 1999-2009). Encuesta de Población Activa (2009). 